\title{
Atmospheric Particulate Analysis Using \\ Angular Light Scattering
}

\author{
M. 2. Hansen
}

(BASA-TH-81112) ATHOSPHERIC PAKTICULATE ARALYSIS USING ANGULAR LIGHT SCATTERING
(MASA) 40 P HC A03/AF AOI CSCL $04 \mathrm{~A}$

$$
\text { G3/46 Unclas }
$$

\section{Submitted to Applied Optics}

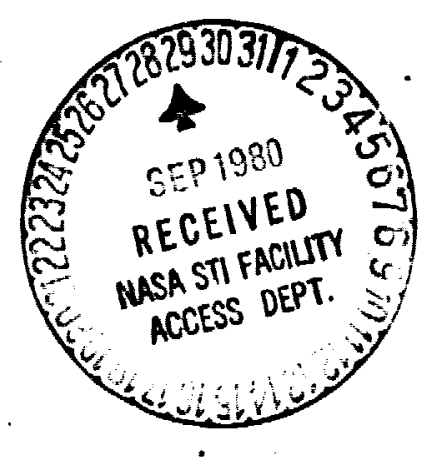

The majority of chis work was completed whlle the author was at the University of Arizona, Institute of Atmospheric Physics, Tucson, 85721. The author is presentiy with the Goddard Space Flight Center, Laboratory for Atmospheric Sciences, Greenbelt, Maryland 20771. 
Using the llight scattering matrix elements measured by a polar nephelometer, a procedure for estimating the characteristics of atmospheric particulates was developed. A theoretical library data set of scattering matrices derived from Mie theory was tabulated for - range of values of the size parameter and refractive index typical of atmospheric particles. Integration over the size parameter yielded the scattering matrix elements for a variety of hypothesized particulate size distributions. A least squares curve fitting technique was used to find a best fit from the library data for the experimental measurements. This was used as a first guess for a nonlinear iterative Inversion of the size distributions. A real index of 1.50 and an Imaginary Index of $\mathbf{- 0 . 0 0 5}$ are representative of the smoothed inversion results for the near ground level atmospheric aerosol in Tucson. 


\section{Introduction}

Angular llght scattering data from the atmosphere near ground level were obtalned with a polar nephelometer designed and constructed at the University of Arizona. ' The angular scattering measurements made with this instrument were processed to acquire the four scattering matrix elements due to particulates from a set of four Intensity measurements at each of a number of scattering angle... The best data avallable from the instrument were used for analysis of particulate characteristics.

-In order to analyze the experimental results, Mie theory, which assumes homogeneous spheres, was applied to develop a theoretical particulate scattering representation for comparison. Mie theory accurately describes the scatter from the small, typically irregular particles found in the atmosphere, however larger particles (in the Mie regime) are not particularly well represented. ${ }^{2}$ Papers have appeared recently on developing a theory to correct for the discrepancles, 3,4 however further development is necessary before these methods can be applled to the extent needed for this study. Therefore, due to the difficulties involved in non spherical analysis and the method of data acquisition,' Mie theory was necessarlly used for the calculations in this paper.

An inversion of the light scattering data was necessary to obtain the best possible representation for the particulates. The application of Inversion methods for remote sensing has been a region of expanding activity since computer development made the necessary manipulations țractable. Early techniques included the Phillips-Twomey linear inversion ${ }^{5,6}$ that was applied by Twomey ${ }^{7}$ to extract vertical temperature 
profiles in the atmosphere. This Ilneer method has been used extensively. with success in the analysis of atmospherlc particulates from multiwavelength extinction data. 8,9

The Inversion of atmospheric aerosol angular scattering data to obtain particulate information has typically met with only marginal success. Westwater and Cohen ${ }^{10}$ felt that the Backus-Gilibert inversion. could retrieve size distributions with angular scattering data from their theoretical study with multiwavelength scattering. Post ${ }^{\prime \prime}$ applied this method to multiple angle scattering measurements from water droplets, but had poor results at sizes below loum in radius. Both Post and Westwater and Cohen used narrow size distributions and still had a deterioration of results at small sizes. Some success has been achieved in inverting bistatic lidar data of atmospheric particulates ${ }^{12}$ with the IInear method, but only a very 1 imited data set was avallable. 13

The reasons for using one inversion scheme over another are almost as varled as the investigators, however the nonlinear algorithm technique of Twomey ${ }^{14}$ has shown promise in retrleving particulate size distributlons and was chosen on this basis for application to angular scattering measurements in this paper.

\section{Data Evaluation Method}

An estimate of the size distribution and refractive index of an atmospheric sample is made by comparing the four scattering matrix elements measured at various angles with the nephelometer with element: produced by theoretical size distributions for various indices of refraction. A library data set on magnetic tape was created using a 
subrout ine by Dave 15 for scattering by a sphere. Matrix elements were recorded for 500 size parameters $[0.3(0.2) 100.1]$ at every integral angle $\left[0^{\circ}\left(1^{\circ}\right) 180^{\circ}\right]$ of scatter for all combinations of a set of real indices of refraction $[1.40,1.45,1.50,1.54,1.60]$ and imaginary indices of refraction $[0.0,-0.003,-0.005,-0.01,-0.03]$. (size parameter, $\alpha$, is $2 \pi$ times the particle radius divided by the wavelength of incident light, $0.5145 \mathrm{~mm}$ in this case.) The range of real indices was chosen to encompass a region from near that of water up past that for sllicates. The Imaginary index values vary from ho absorption as for water to a value of -0.03 which is near what $\mathrm{King}^{16}$ has observed.

Subsequently, these data are integrated over the size parameters for Junge and two-slope size distributions (Figs. 1-3). The Junge size distributions are calculated by setting

$$
\frac{d N}{d r}=C r^{-(v+1)}
$$

where $N$ is the particle number concentration, $r$ is the particle radius, C is a normalization value set to $\mathrm{g}$ ive $100 \mathrm{\mu g} / \mathrm{m}^{3} \mathrm{mass} l$ loading, and $v$ varles over a typical range from 2.0 to 4.0 . in 0.2 steps. The two-slope size distributions are calculated by setting

$$
\frac{d N}{d r}=C \frac{\left[1+\left(r / r_{B}\right)^{v_{2}}\right]}{\left[1+\left(r / r_{A}\right)^{v_{1}}\right]}
$$

where all combinations of $r_{A}=0.04 \mu \mathrm{m}, r_{B}=0.4$ and $1.0 \mu \mathrm{m}, v_{1}=2.0$, 3.0, and 4.0, and $v_{2}=0.0,1.0$, and 1.5 are used. These parameters were chosen to give turnover values between 0.01 and $0.1 \mathrm{\mu m}$. These are above the values observed by Twomey, 17 but a higher turnover point is necessary if any effect were to be observed on the scattering data. 
Comparlsons are made between these slze distributions and real

date by allowing the mass loading to vary to give best least squares

fit. The quality of the fit is determined by the size of $H$, given by

$$
H=\sum_{1}\left(b_{1}-\xi d_{1}\right)^{2}
$$

where $\xi$ is evaluated at $\Sigma d_{1} b_{1} / \Sigma d_{1}{ }_{1}^{2}$ for a minimum $H$ and functions as a mass loading adjustment to obtain the best fit. $b_{i}$ is the observed aerosol scattering matrix element, and $d_{1}$ is the corresponding theoretical matrix element normalized for $100 \mu \mathrm{g} / \mathrm{m}^{3}$. Biasing of the data according to scattering volume is also used. Outside the range of the size parameters on tape, the number concentrations are inadequate (for any realistic size distribution and visible wavelengths of light) to affect the observed scatter and are neglected. The tabulated comparisons are evaluated to find the best least squares fit with reasonable mass loading and to observe any tendencies such as sensitivity to the parameters that are varied.

Due to the similartty of many of the kernels, little information is gained by using a complete range of angles to obtain a size distribution. The additional time involved in making excessive measurements can also be detrimental due to possible changes in the sampled aerosol. Therefore, consideration should be given to which angles are most critical. Angles where the scattered light Is minimal have more error and should be avolded. Also, angles where the scattered radiance changes very quickly are affected more by positioning error in the detector. By considering angular scattering measurements made on monodisperse particles, ${ }^{2}$ one finds that for larger nonspherical laboratory aerosols, 
Mie theory seoms to hold best for angles less than about 40 degrees. Smaller aerosols (as they approach the Rayleloh regime) tend to follow Mle theory qulte well. This leads one to inspect where the larger aerosols contribute to the scatter. By looking at Figs. 4 and 5 , one observes that the difference due to the large aerosols is 1 imited mainly to the forward few degrees. This not only implles that Mle theory should hold better for a typical aerosol size distribution than for single large aerosol studies, but that if one desires information content from the larger aerosols, measurements must be made in the forward direction or little information above $1 \mu \mathrm{m}$ is obtained for typical size distributions.

\section{Inversion Technique}

Continuing with the next step, the inversion method is considered. A nonlinear algor ithm was developed by Chahine 18 which essentially assumed del ta functions for kernels but acquired inherent instabilities due to increased high frequency content when measurements were numerous. Chahine's algorithm was modified by Twomey ${ }^{14}$ to include the entire nonzero region of the kernel. This eliminated the detrimental factor of superfluous data and, in fact, caused the inversion to improve with additional data due to an effective decrease in measurement error.

The nonlinear inversion has also shown an ability to cope with measurement errors, which greatly strengthens its position in application to. the aerosol size distribution problem. The Iterative algorithm is 


$$
f^{\prime}(r)=1+\left[\frac{g(s)}{\rho^{0}(r) k(r, s) d r}-1\right] \frac{k(r, s)}{k(s)_{\max }} f^{0}(r)
$$

where $f^{0}(r)$ is the initial guess size distribution, $k(r, s)$ is the kernel value (the theoretical scattering matrix element for single particle), $g(s)$ is the actual measured scattering matrix element for the collection of particlss, and $f^{\prime}(r)$ is the modified size distribution. Varlable $r$ refers to the particle radius or size parameter, and varlable s refers to a specific matrix element measurement. Examination of the kernels shows that a lot of fine structure typically occurs (figs. 6-9), particularly near backscatter. Whereas this might be expected to be beneficial for fine resolution, in practice this structure is too high a frequency to be effective in improving the inversion accuracy. Since atmospheric aerosol size distributions do not seem to have these wild osclilations and nelther do the observed scattering measurements, the fine structure would not seem necessary to resolve that data even if it were effectively usable. In fact, it might be desirable to use smoothing of the kernel to assist in obtaining a stable solution. The power. spectra of the kernels also show that the middle frequencies are of ten deficlent (Fig. 10), and occasionally even low frequencles are absent (F/g. 11 ). This is a strong negative factor in the application of scattering kernels to inversion techniques.

simple quadrature is used for the integral with the kernels being read from magnetic tape. Each data value is successively iterated once through all the particle sizes on tape, modifying the size distribution according to the kernel's weighting effect. The weighting is scaled to less than or equal to one by dividing by the maximum kernel value for a particular angle and matrix element. After each unknown in the set has been determined from the first iteration, the process is repeated until 
the final distribution is obtained. Although the Inversion lends itself easlly to programming, care is stlll required in Its application.

IV. Inversion of Theoretical Data

Inltial runs of the inversion program were made on data generated from Mie theory to establish the accuracy of the inversion with scattering kernels. The nephelometer measures the radiance of light scatter which is a function of the particles' scattering cross sections times their concentrations. It was necessary to weight the scattering kernels according to an initial, first guess size distribution to obtain reasonable results. Otherwise, there was a strong tendency for the inversion to adjust the large particle concentrations to the point of instability. The runs were made using only the $M_{2}$ and $M_{1}$ elements ${ }^{2}$ from five forward angles and two backward angles. These were chosen to maximize information content with a minimum of data. A speclal problem occurs in applying inversions to the $S_{21}$ and $D_{21}$ elements as it is pessible for the theoretical and measured values to be of opposite sign due to errors in the measurements or in the first guess size distribution. This would imply a negative particle concentration that is not allowed. Runs were made with theoretical data from Junge distributions. A $v$ of two, index of $1.54-.0051$, and mass loading of $38 \mu \mathrm{g} / \mathrm{m}^{3}$ were used for a first guess, as these values produced a close fit for one of the real aerosol runs. A method of overrelaxation was settled upon as the best technique for applying the algorithm. It has the format

$$
f^{\prime}(r)=\left\{1+M^{R}\right\} f^{0}(r)
$$


where

$$
H=\left[\frac{g(s)}{f^{\prime}(r) k(r, s) d r} \cdot I \frac{k(r, s)}{k(s)_{\max }}\right.
$$

The absolute value of $M$ is ralsed to the power $R$, and that quantity takes the same positive or negative sign as $M$.

Not only did overrelaxation with values of $R$ less then one speed up convergence, but it improved the results grestly (Fig. 12). Too large of an overrelaxation, however, caused ostillations. A value of 0.7 for $R$ produced the best stabllity and convergence although 0.5 gave the fastest convergence. Excessive iterations are not only costly, but tend to produce a more highly structured, atypical size distribution. This is avolded by terminating the iterative process after successive iterations with less than 0.2 percent improvement in error.

The Inversion program was run with theoretical data to observe the effect of varlous size distribution first guesses on the results of the Inversion. Large differences between the actual and initial guess mass loading were difficult for the inversion to handle if no internal mass loading adjustment is included in the program (Fig. 13). This serves to point out graphically the size range of information content of the data and the kind of structure that can occur due to the oscillatory nature of the kernels. The response in the region of information content is adequate to indicate the proper correction necessary (i.e. higher or lower) in the mass loading. Differences between the actual and initial guess $v$ values (Fig. 14 ) have much less effect on the Inversion. Examination of the region of convergence does show that the 
scuttering is mainly sensitive to particles in the 0.2 to 2 um range and subsequently. this is the region where results are applicable.

Random érror was added to the thenretical date to observe its effect on the inversion. Nelther 4 nor 11 percent error had a significont effect on the inverted size distribution. This result is essential to obtaining reallstic inversions wich experimental data. The convergence IImit on the error (Fig. 15) was, in fact, Indlcative of the percentage error in the data; however, more study of this point is necessary for verification.

The linear inversion mothod was also applied to this problem initially. However, it could not invert the data unless the error level was 1 percent or less. This is an unreallstically low value, especlally since Mie theory alone can account for more than 1 percent error. Therefore, the Ilinear method was dropped.

\section{Experimental Results}

After checking the ablilty of the inversion to reproduce theoretical date, experimentel date were anelyzed.

\section{A. Curve fitting}

By comparing the experimental data with the theoretical library dota, best fit was obtained. Typlcally, about 20 scattering angles with four matrix elements at each angle were used. The fit was weighted by the cosecant of the scattering angle to allow more bias for larger scattering volumes. After checking the date fit with matrix elements produced by both Junge and two-slope slze distributlons and using truncated date sets that excluded measurements of smaller magnitude, an 
estimate for the aerosol size distribution was obtained. The nephelometer runs for Harch gth ware overaged and gove a Junge best fit with $m=1.50-.0031, v=2.1$, and mass loading $-36 . \mu g / m^{3}$. The two-slope best fle for the same data was $m=1.50-.0031, v_{2}=2.0, v_{2}=0$, $r_{A}=.04 \mu \mathrm{m}, r_{B}=1.0 \mu \mathrm{m}$, and mass loading $=80 \mu \mathrm{g} / \mathrm{m}^{3}$.

The mass landing is not extremely critical as the largest particles dominate this value while thay have much less effect on the ectual light scatter on wich the measurements are based. Another set of runs on March loth was averaged to ylels a Junge best fit with - $1.47-.0051, v=2.0$, and mass loading $=47 \mathrm{\mu g} / \mathrm{m}^{3}$ and two-slope itt with $m=1.50=.0041, v_{1}=2.0, v_{2}=0.0, r_{A}=.04 \mu m_{1} r_{B}=1.0$ wist, and mass loading $=100 \mathrm{\mu g} / \mathrm{m}^{3}$. Figs. 16 and 17 show typlcal graphs of the experimentally masured matrix elements plotted in comparison with the theoretical data produced by the corresponding best fit size distribution. As expected, the curves match closely near the forward direction which is where Mls theory is belleved to hold best and where the strongest welyhting is placed on the least squares fit. The two-slope end Junge distributions which gave the best fits are of simllar form over the size range of information content. Therefore, the simpler Junge distribution was chosen for combining the March data which gave an overall oerosol characterizetion of $m=1.49-.0041, v=2.0$, and mass laading $=40 \mathrm{ug} / \mathrm{m}^{3}$.

The strongest sens!tivity for the ranges of parameters under consideration was observed to be the slze distribution slopi... hext in Importance was the imaginary Index, and the least sensitive was the real Index. 


\section{B. Inversion of Size Distributions}

Further Improvement in the size distribution estimate is attempted by using the Ilbrary data closest to the curve fitting results as a first guess for the Inversion. Falrly consistert results are obtalned by the inversion (as shown by Fig. 18 for the March 9th data) even if the Initlal $v$ value is verled above or below the curve fitting results.

The convergence of the Inversion is shown by the RMS error snoothly approaching minimun values as the number of iterations increases (F/g. 19). Even when the initial guess is greatly in error from the data, the RMS error Iterates down to the 15 percent range whlch is representative for -11 the runs. Attempts were made to improve the minimum RMS error of the Iterated Inversion by using different Indices of refraction; however, this exerclse just verified the cholces of the curve matching technlque. Probable causes of thls large of a convergence limit (if it is truly Indleative of the experimental error) are covered in a preceding paper.'

Other inverted size distributions with varlous initial guesses ore shown In FIgs, 20 and 21. Twelve Inversions were averaged and smoothed to obtain a representative inverted size distribution (F/g. 22). The results ore most closely modeled by a Junge size distribution with $m=1.50-.0351, v=1.8$, and mass loading of about $60 \mathrm{\mu g} / \mathrm{m}^{3}$. The curve is purposely truncated so that only the region of sensitivity is shown. A maximum serosol number concentration (or turnover point) of the size distribution is not observed since the sensitivity of the kernel drops off sharply below 0.2 un while typlas turnover polnts occur near 0.01 un for the ground level Tucson aerosol. 
vi. Conclusions and Further Study

The tachnique developed in this paper has yielded estimates of atmospheric aerosol characteristics--vis., size distrlbutions and real and imaginary indices of refraction--from measurements of matrix scattering elements at various angles. The results are reasonable in comparison with other work ${ }^{19-22}$ in this field, and the size distributions match quite well near $0.1 \mu \mathrm{m}$ with nuclepore filter measurements ${ }^{16}$ that were made at the same location but are sensitive to particles from $0.1 \mu \mathrm{m}$ on down. To achleve a characterization of the ground level Tucson aerosol, measurements should be made routine!y over an extended period.

Improvement in the stability of the inversion technique might be achieved by smoothing the kernels to remove the higher frequency information. Further sophistication could be achieved by expanding the inversion routine to include fitting the inversion results to a smooth analytic function and using this as a new first guess.

A detalled study of the information content would be of special interest. Initial work in this area has shown that the scattering data used in this study are in the region of optimum information content. This could lead to an instrument with a minimum number of fixed detectors set at carefully chosen angles which would eliminate the need to move the detector and speed the measurement time.

The author would like to thank Dr. Benjamin M. Herman and Or. Walter H. Evans for their assistance on this project. This research was funded by the Office of Naval Research under Grant \#NO0014-75-C-0208, and computer time was furnished by the Natlonal Center for Atmospheric Research which is sponsored by the National Science Foundation, under project \#35021004. 


\section{References}

1. M. 2. Hansen, Appl. Opt. submitted for publication.

2. R. G. Pinnick, D. E. Carroll, and D. J. Hofman, Appl. Opt. 15, $384(1976)$.

3. P. Chylek, G. W. Grams, and R. G. Pinnick, Science 193, 486 (1976).

4. C. Acquista, App1. Opt. 17, 3851 (1978).

5. D. L. Phlllips, J. Assoc Comput. Mach. 9, 84 (1962):

6. S. Twomey, J. Assoc. Comput. Mach. 10, 97 (1963).

7. S. Twomey, Mon. Wea. Rev. 94, 363 (1966).

8. G. Yamamoto and M. Tanaka, Appl. Opt., 8, 447 (1969).

9. M. D. King, D. M. Byrne, B. M. Kerman, and J. A. Reagan, J. Atmos. Scl. $35,2153(1978)$.

10. E. R. Westwater and A. Cohen, Appl. Opt. 12, 1340 (1973).

11. M. J. Post, J. Opt. Soc: Am. 66, 483. (1976).

12. B. M. Herman, S. R. Browning, and J. A. Reagan, J. Atmos. Sci. 28, $763(1971)$.

13. D. M. Byrne, Ph.D. Dissertation, U. Arizona (1978).

14. S. Twomey, J. Comp. Phys. 18, 188 (1975).

15. J. V. Dave, "Subroutines for Computing the Parameters of Electromagnetic Radiation Scattered by a Sphere," IBM Report 320-3237 (IBM Scientific Center, Palo Alto, Calif., 1968).

16. M. D. King, J. Atmos. Scl. 36, 1072 (1979).

17. S. Twomey, J. Atmos..Sci. 33, 1073 (1976).

18. M. T. Chahine, J. Opt. Soc Aii. 58, 1634 (1968).

19. J. D. Lindberg and L. S. Laude, Appl. Opt. 13, 1923 (1974). 
20. J. D. Spinhirne, J. A. Reagan, and B. M. Herman, J. Appl. Meteorol. 19. $426(1980)$.

21. G. W. Grams, 1. H. Blifford, Jr., D. A. Gillette, and P. B. Russell, J. Appl. Meteorol. 13, 459 (1974).

22. J. A. Reagan, D. M. Byrne, M. D. King, J. D. Spinhirne, and B. M. Herman, J. Geophys. Res. 85, 1591 (1980). 
Fig. 1. Junge size distribution curves.

Fig. 2. Two-slope size distribution curves.

Fig. 3. Scattering element $M_{2}$ integrated over Junge size distributions.

Fig. 4. Scattering element $S_{21}$ integrated over a Junge size distribution for two particle size ranges.

Fig. 5. Scattering element $M_{2}$ integrated over a Junge slze distribution for two particle size ranges.

Fig. 6. Weighted scattering element $M_{2}$ for single particles.

Fig. 7. Weighted scattering element $M_{1}$ for single particles.

Fig. 8. Scattering element $M_{1}$ for single particles.

Fig. 9. Scattering eiement $M_{2}$ for single particles.

Fig. 10. Power spectrum of $\mathrm{M}_{2}$.

Fig. 11. Power spectrum of $D_{21}$.

Fig. 12. Convergence of iterative inversion for theoretical data with no error.

Fig. 13. Theoretical size distribution inversions for various mass loading initial guesses.

Fig. 14. Theoretical size distribution inversions for various Junge slope initial guesses.

Fig. 15. Convergence of iterative inversion for theoretical data with 11 percent error.

Fig. 16. $M_{2}$ scattering matrix element.

Fig. 17. $s_{21}$ scattering matrix element.

Fig. 18. Size distribution inversions for March 9 th experimental data. 
Fig. 19. Convergence of iterative inversion for experimental data with various mass loading initial guesses.

Fig. 20. Size distribution inversions for March 4th experimental data.

Fig. 21. Size distribution inversions for March loth experimental data.

Fig. 22. Average of inverted size distributions. 


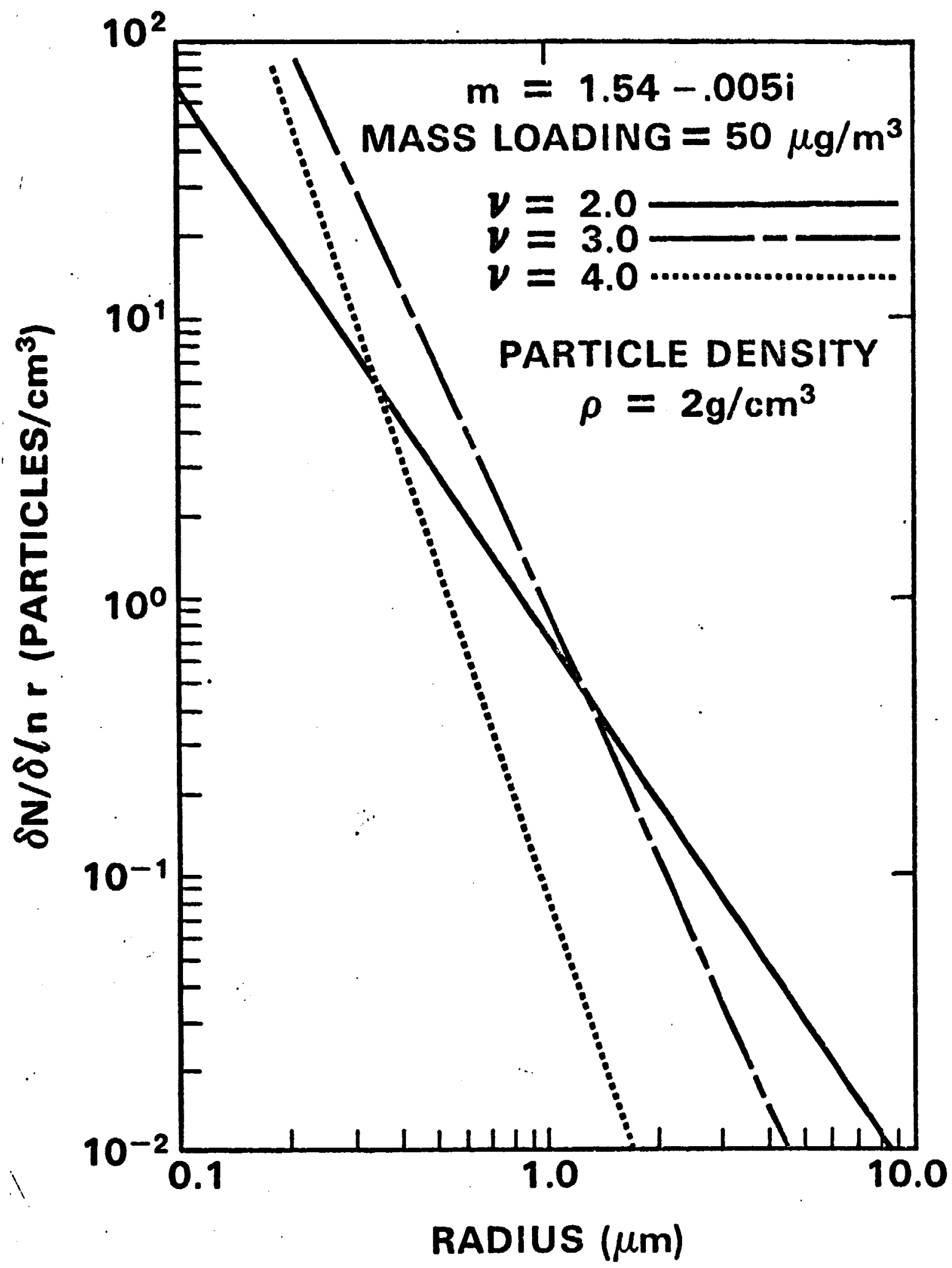

Fig. 1. Junge size distribution curves. 


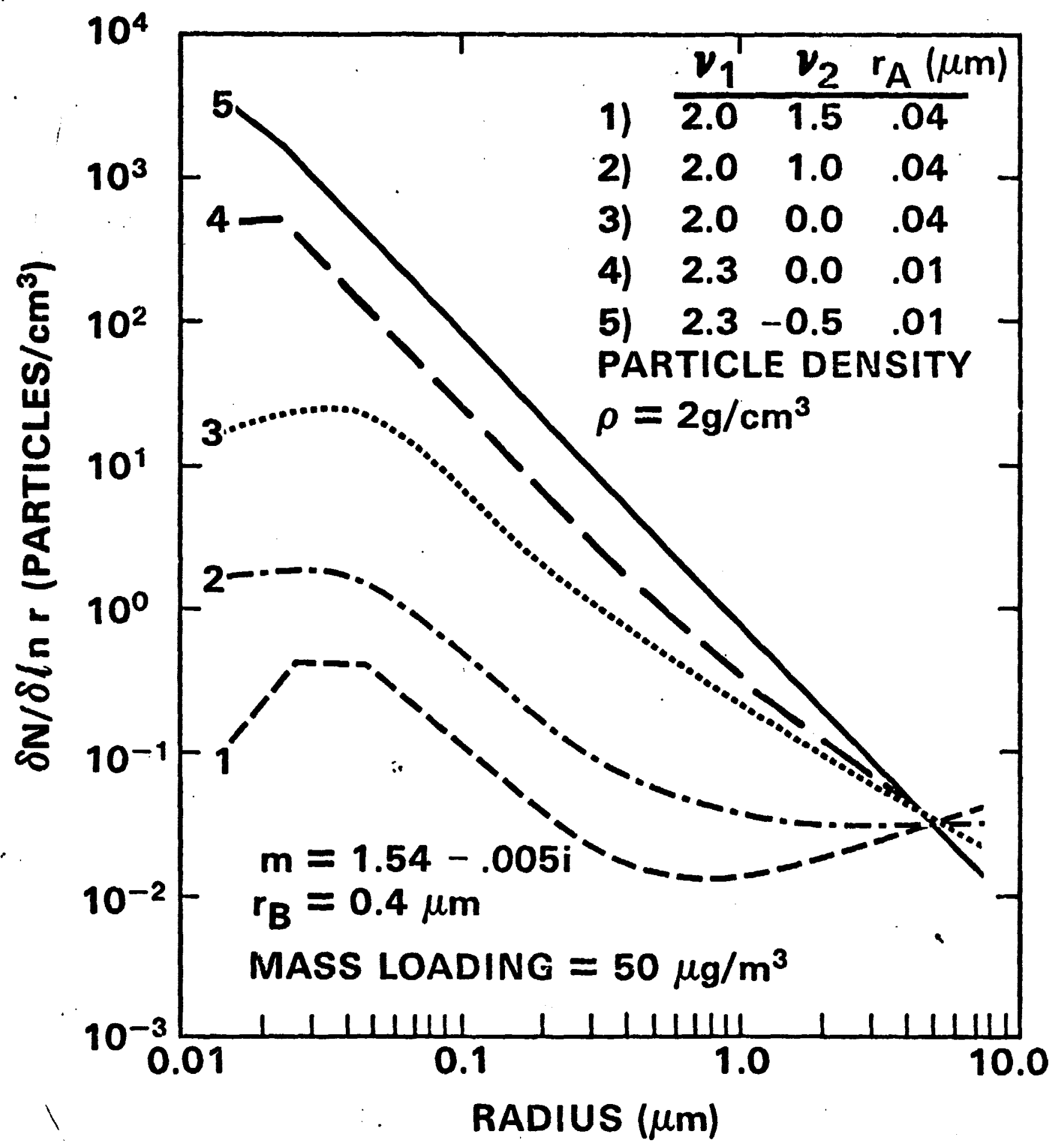

Fig. 2. Two-slope size distribution curves. 


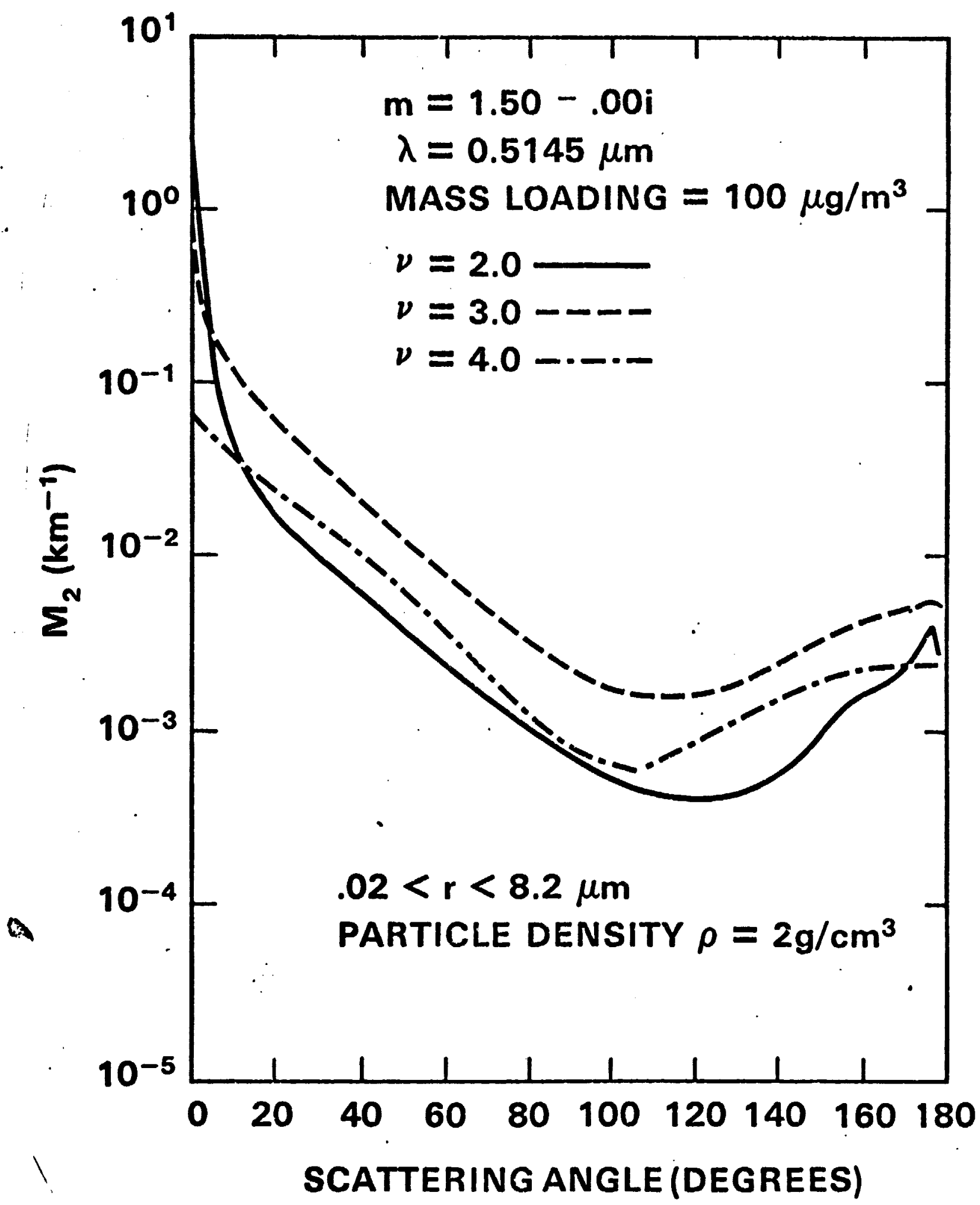

Fig. 3. Scattering element $M_{2}$ integrated over Junge size distributions. 


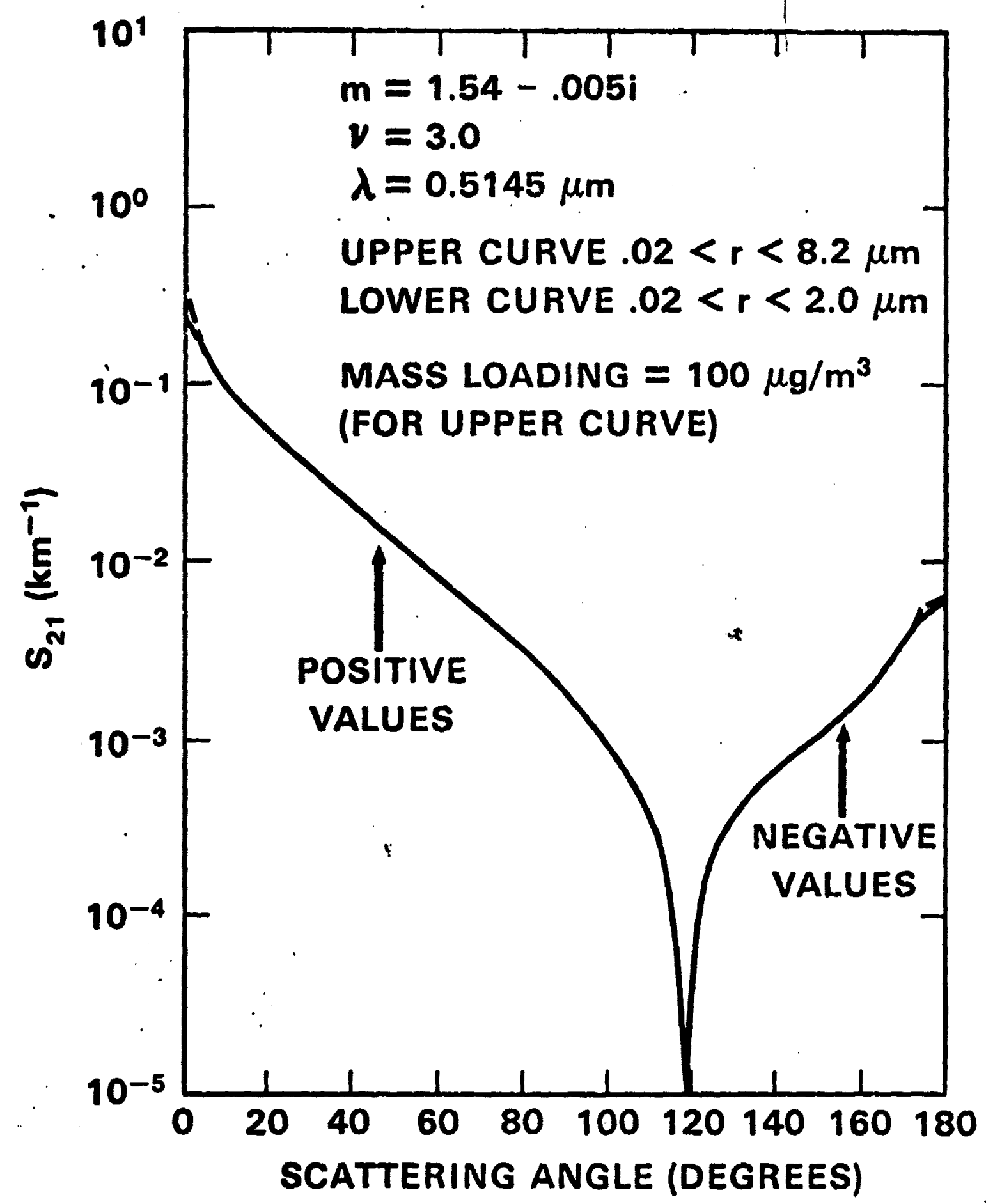

Fig. 4. Scattering element $S_{21}$ integrated over a Junge size distribution for two particle siz ranges. 


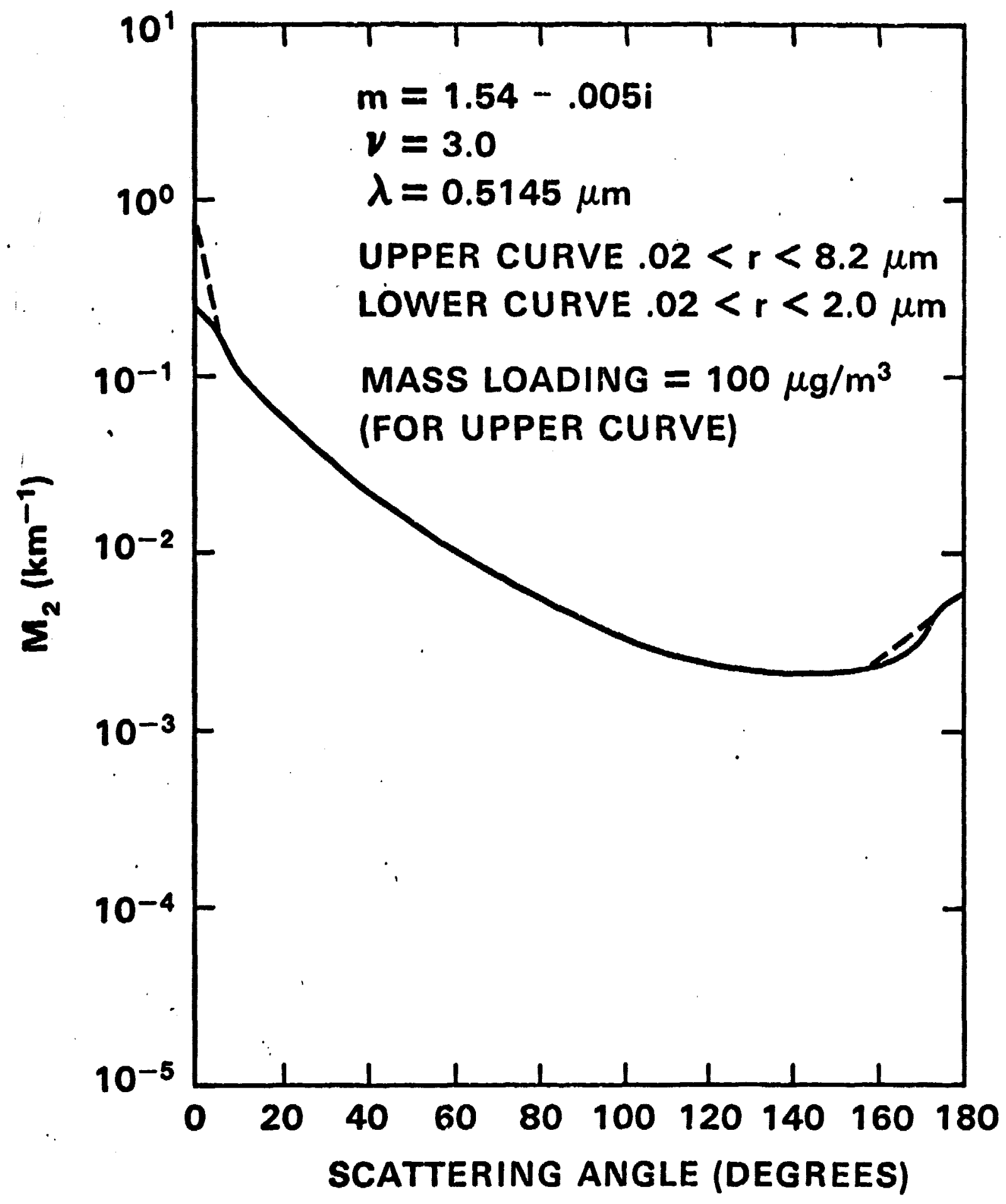

Fig. 5. Scattering element $M_{2}$ integrated over a Junge size distribution for two particle size ranges. 


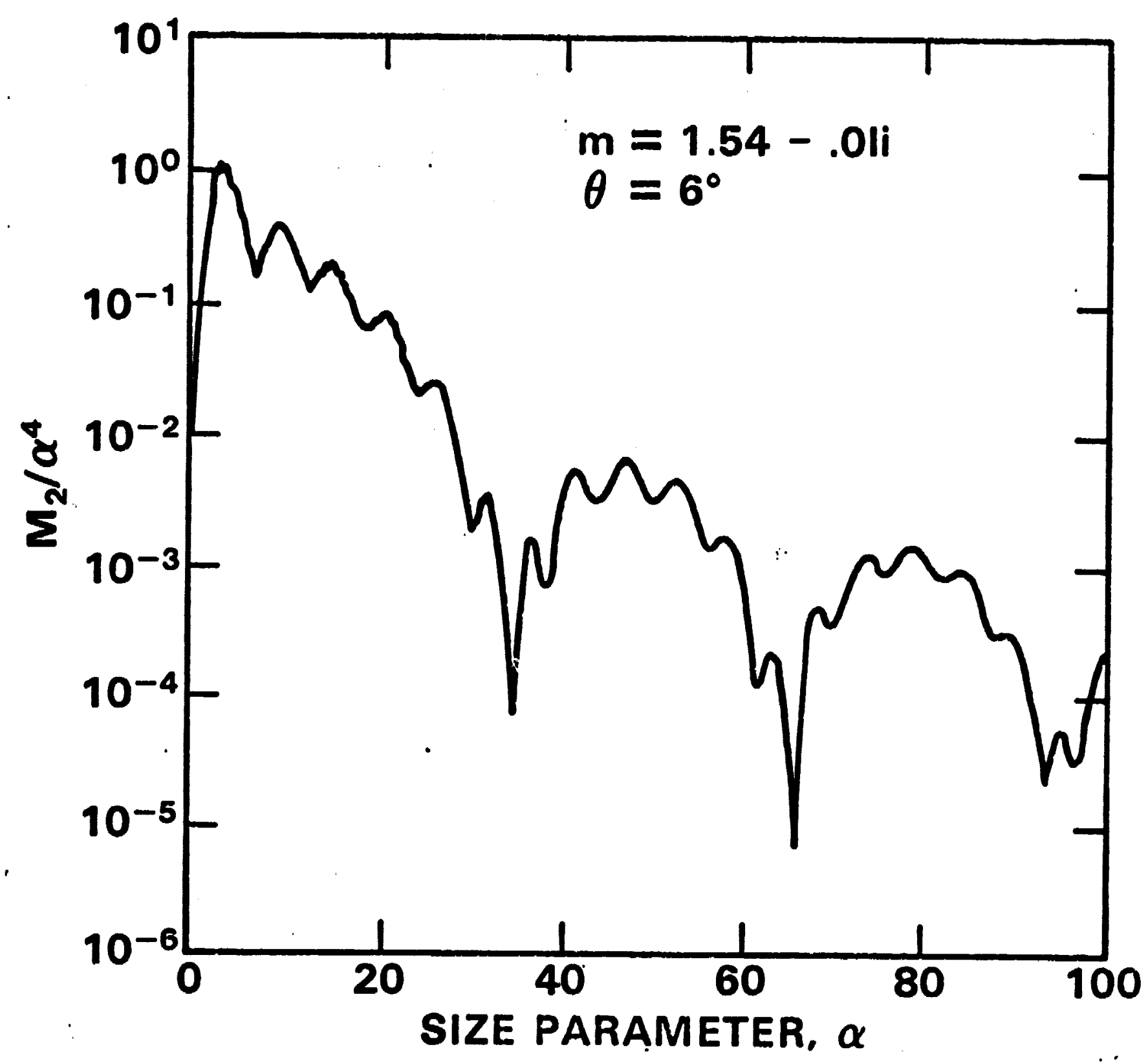

Fig. 6. Weighted scattering element $M_{2}$ for single particles. 


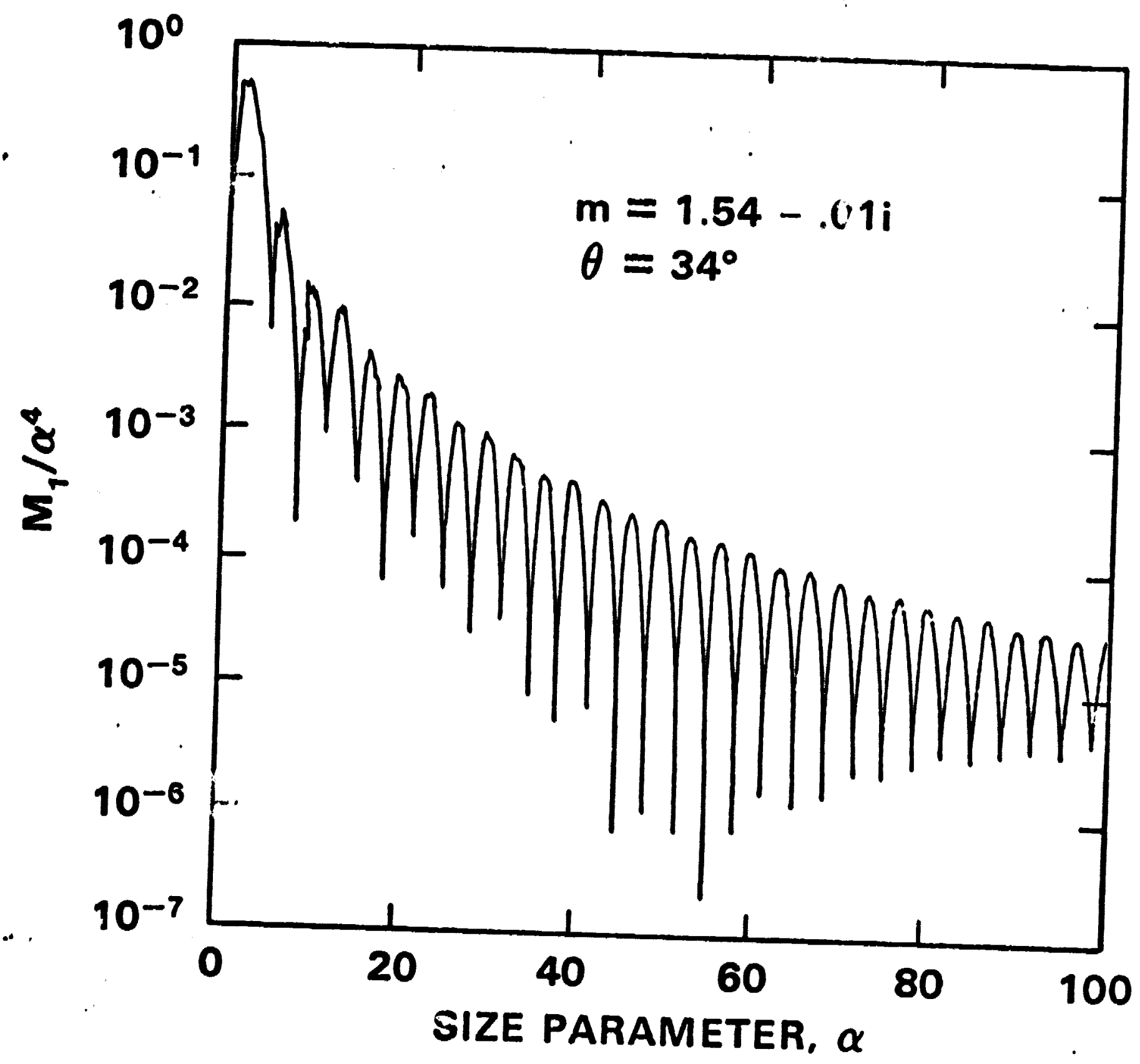

Fig. 7. Weighted scattering element $\mathrm{NI}_{1}$ for single particles. 


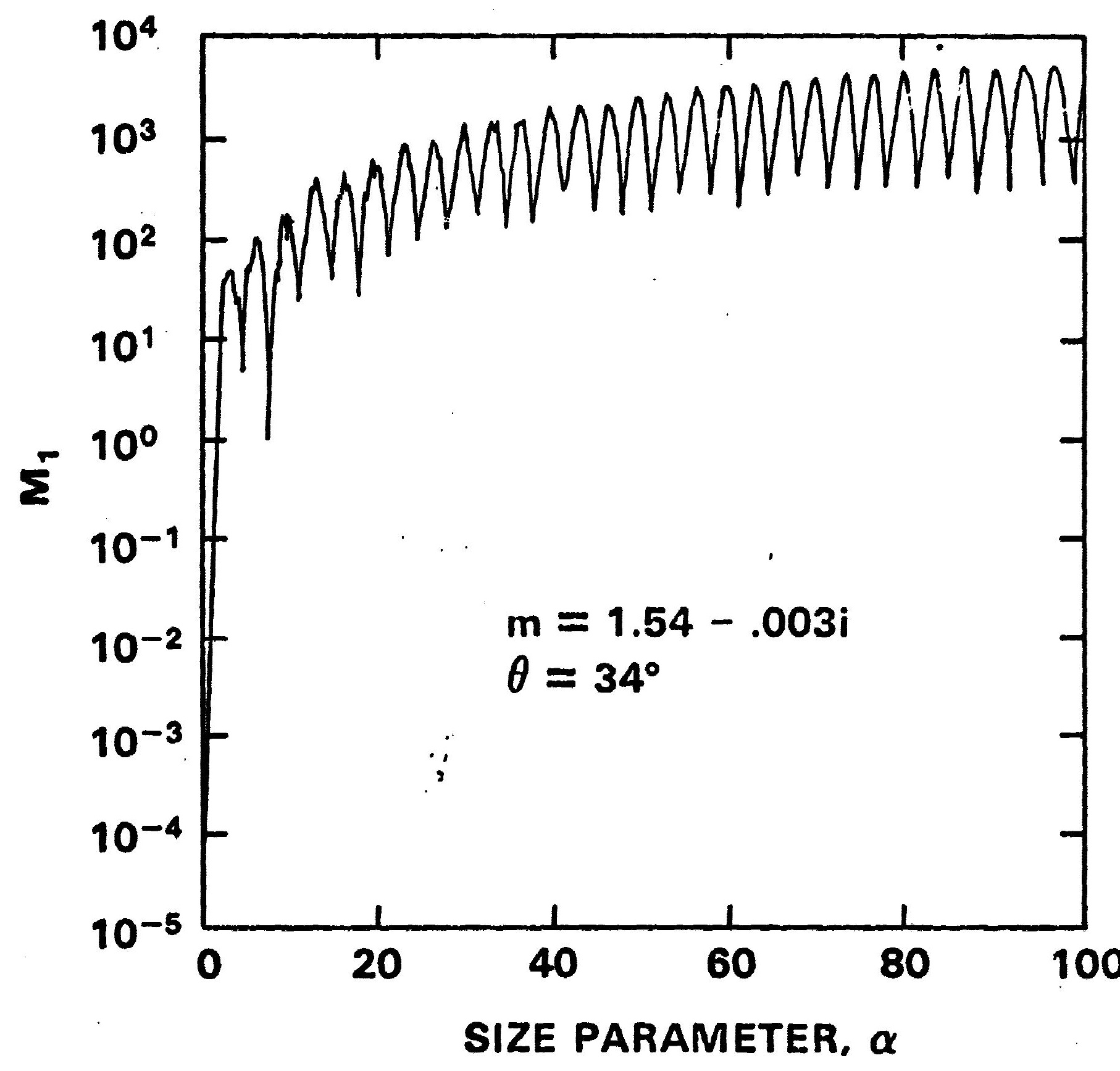

Fig. 8. Scattering element $M_{1}$ for single particles.

or.

$$
\therefore \text { VALCLOS }
$$




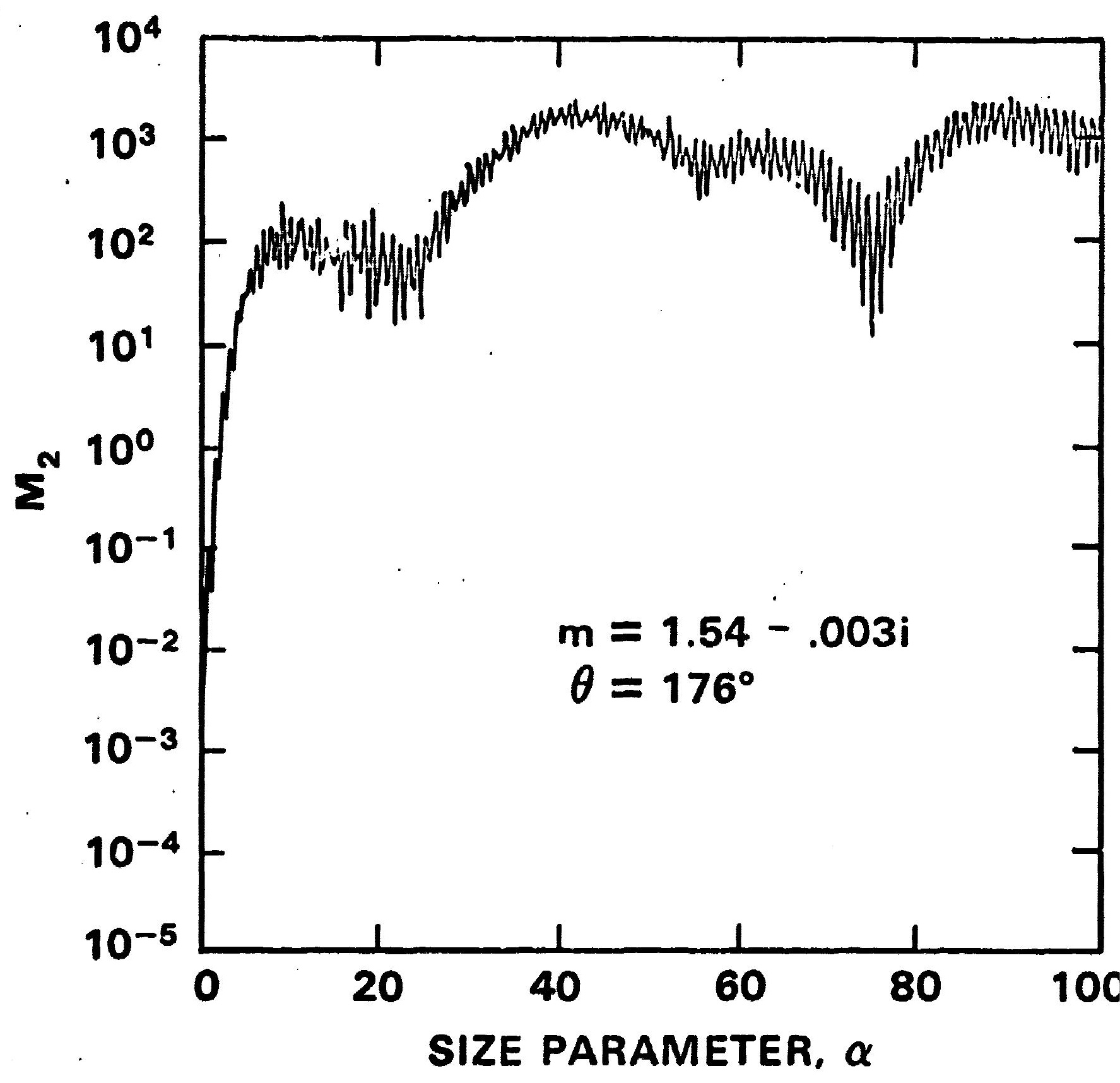

Fig. 9. Scattering element $M_{2}$ for singl particles. 


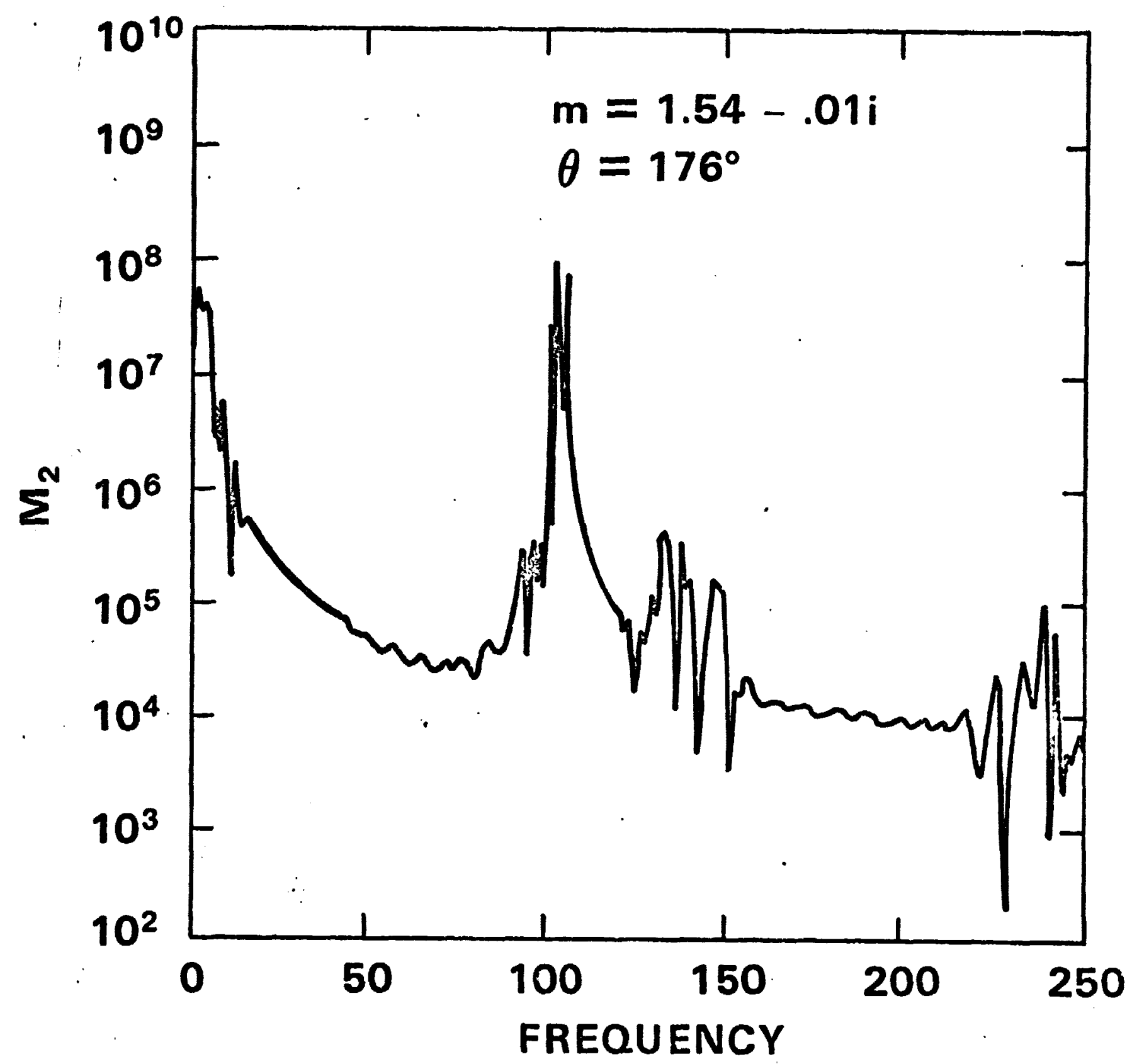

Fig. 10. Power spectrum of $M_{2}$. 


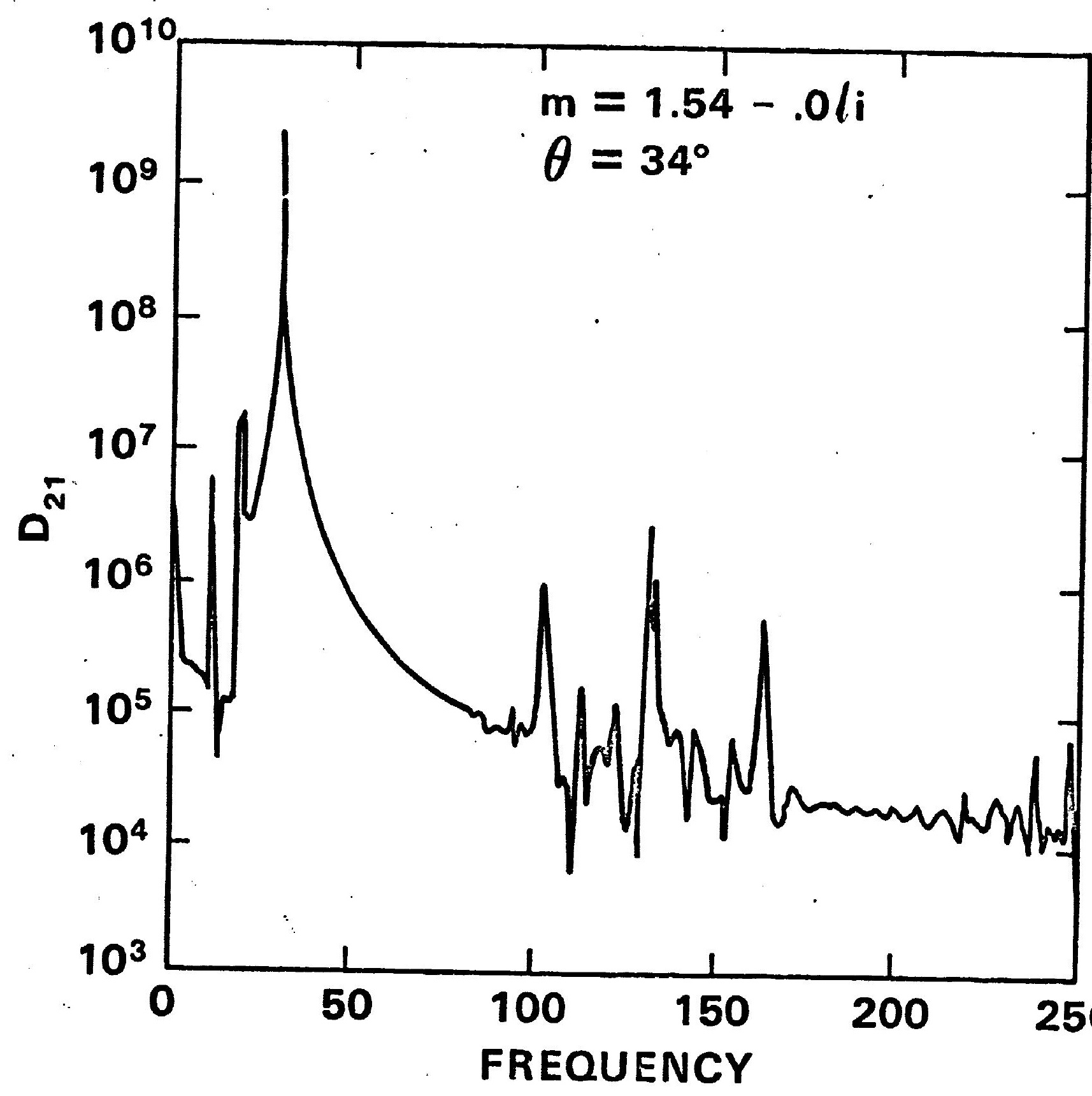

Fig. 11. Power spectrum of $D_{21}$. 


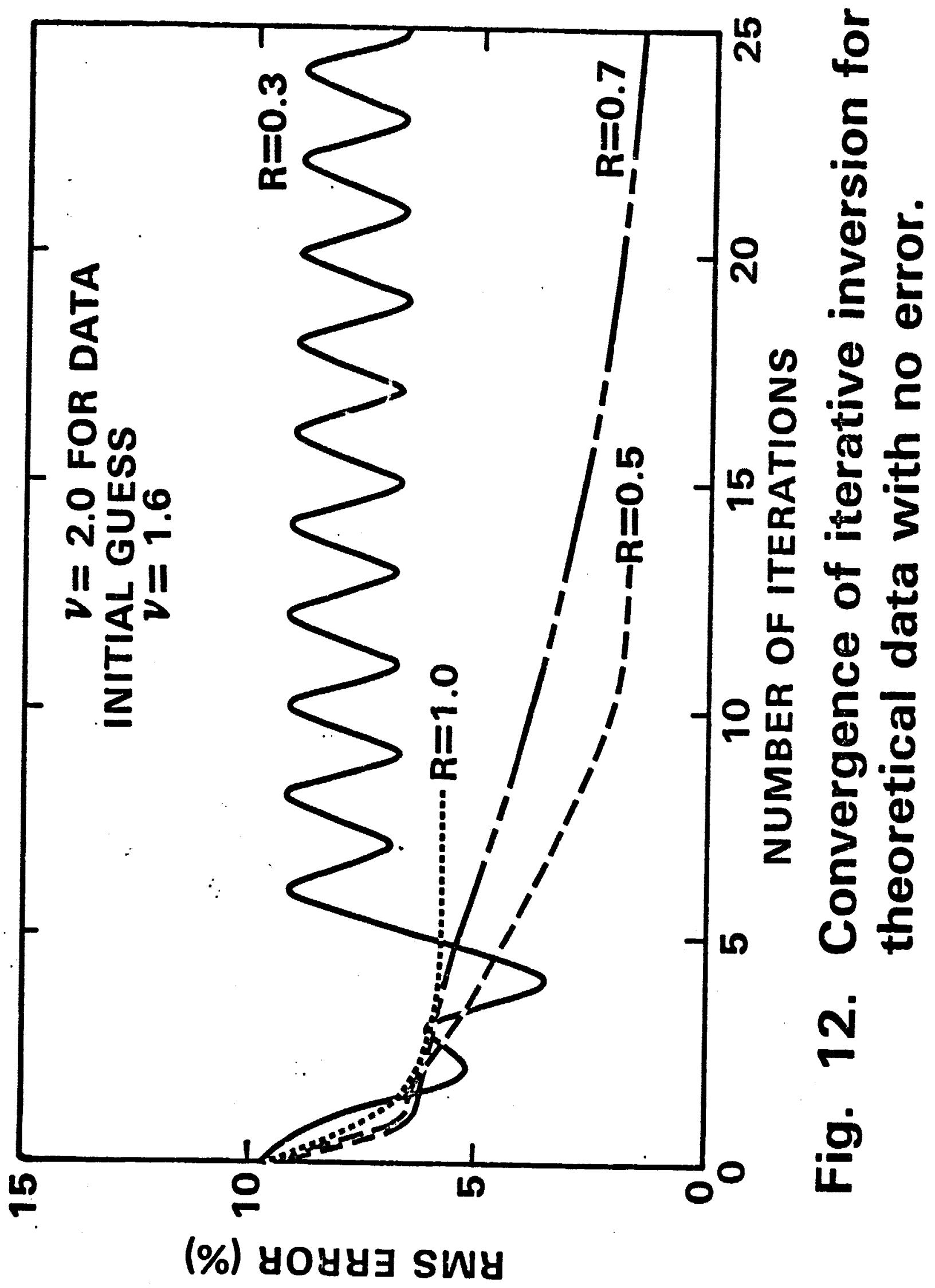

ORIGINAT PAGE IS

OF PO ' IITY 


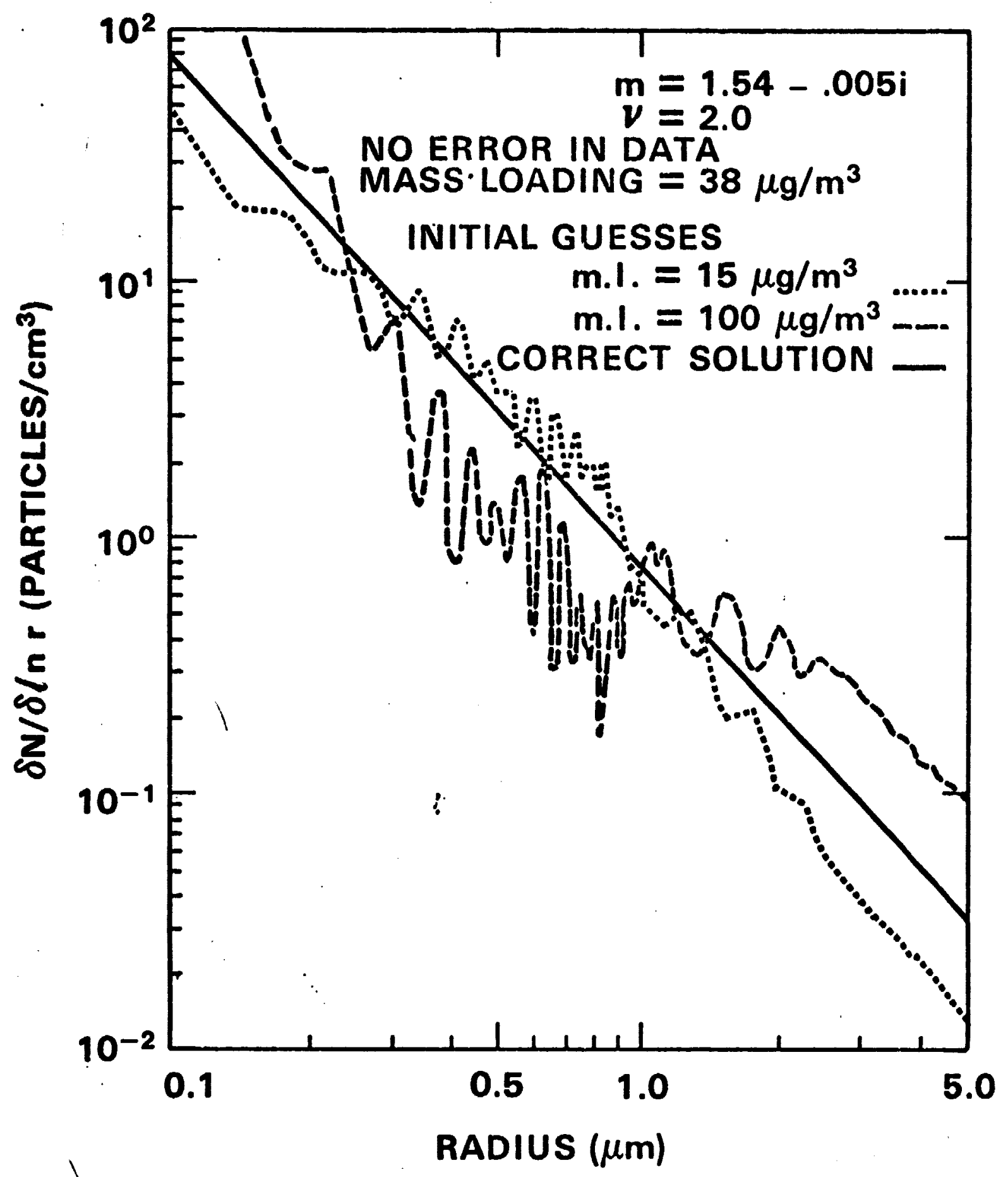

Fig. 13. Theoretical size distribution inversions for various mass loading initial guesses. 


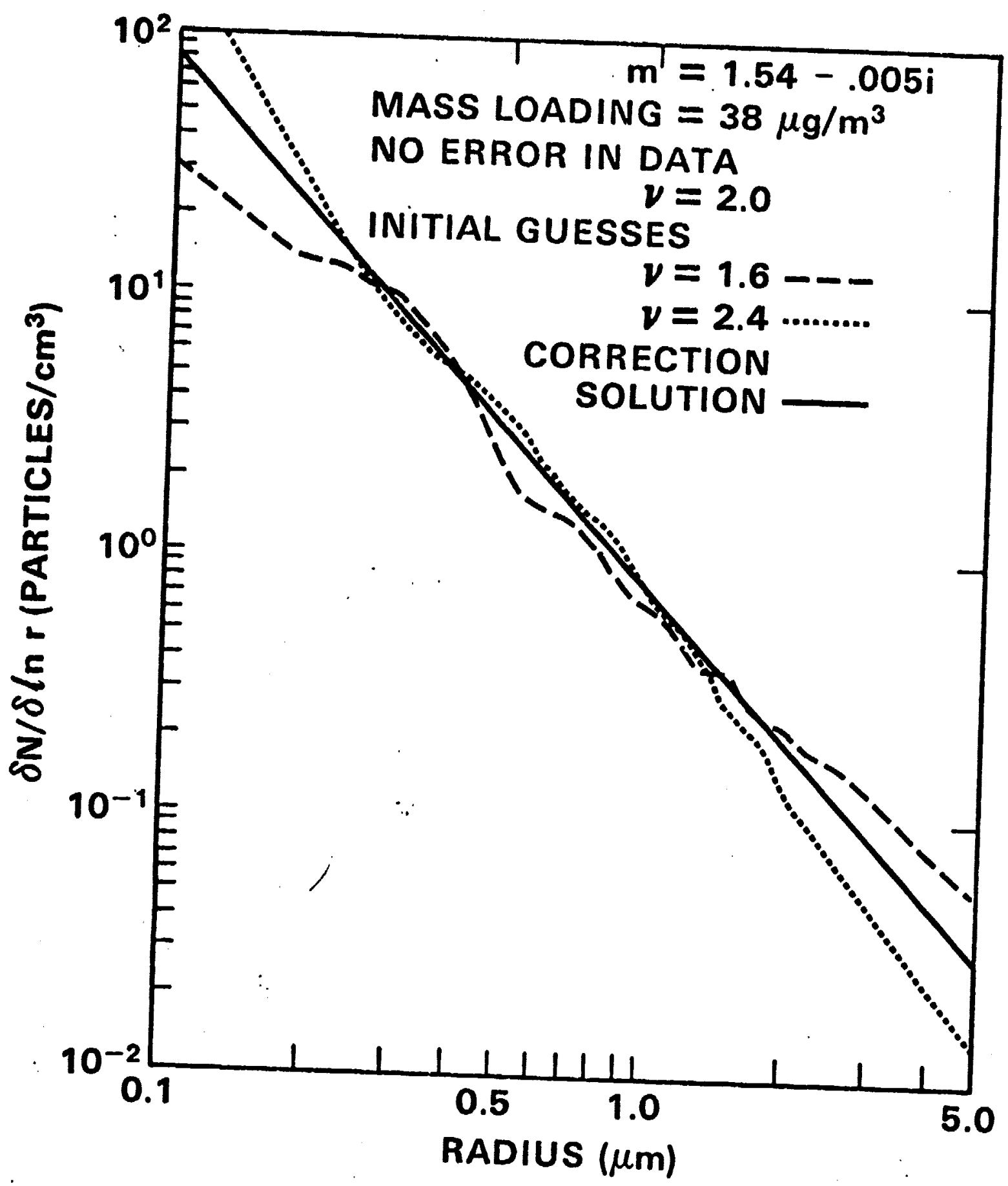

Fig. 14. Theoretical size distribution inversions for various Junge slope initial guesses. 


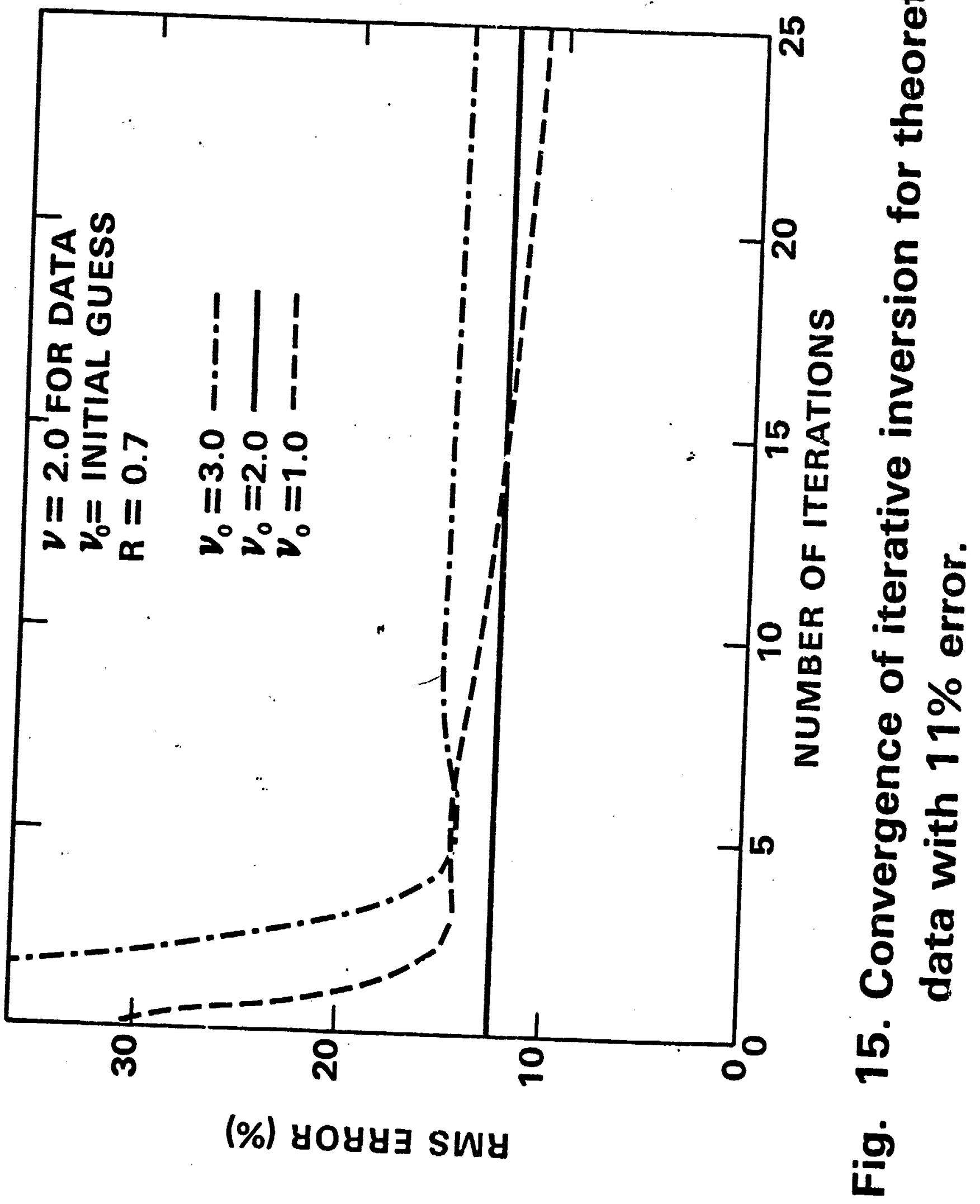




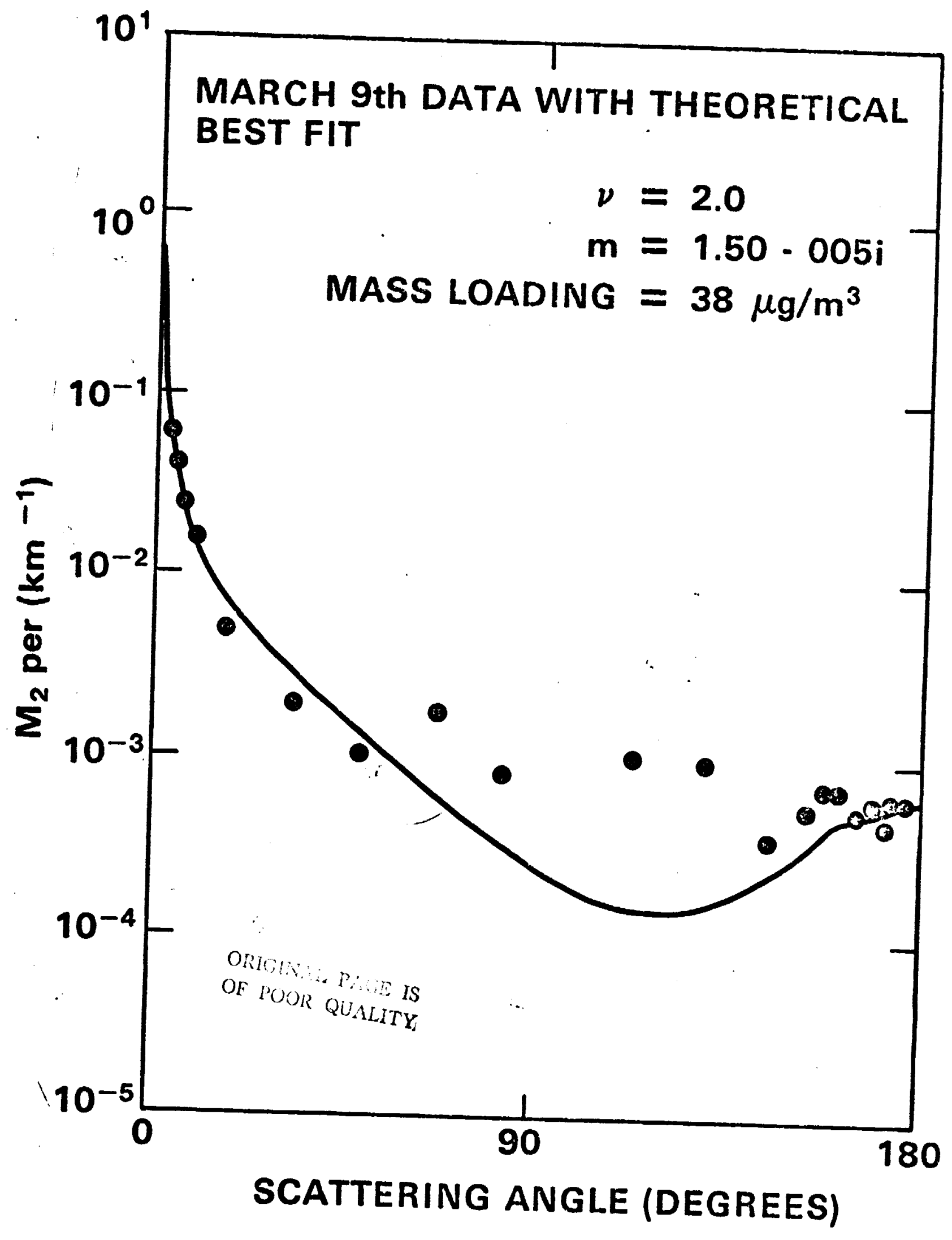

Fig. 16. $M_{2}$ scattering matrix element. 


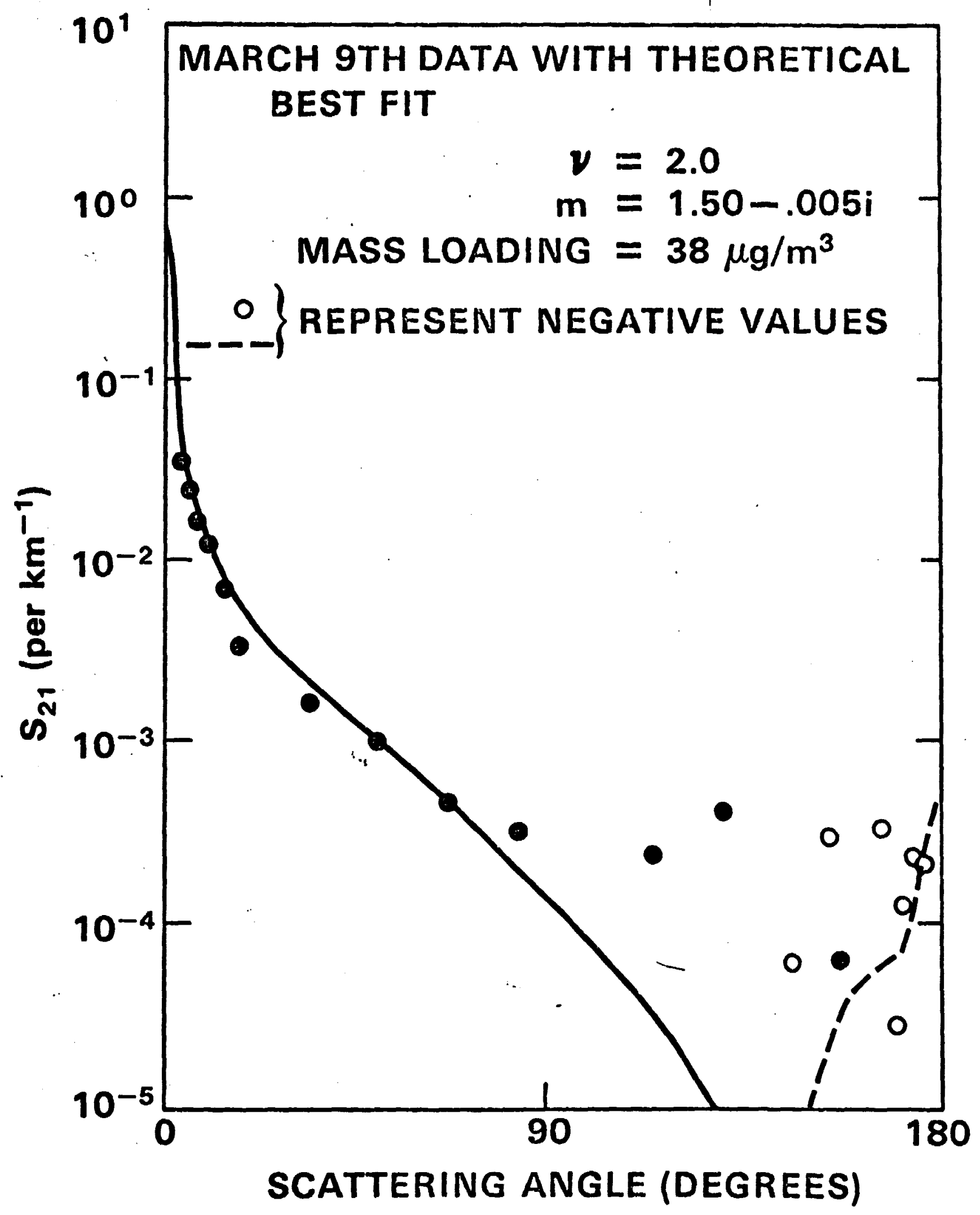

Fig. 17. $S_{21}$ scattering matrix element . 


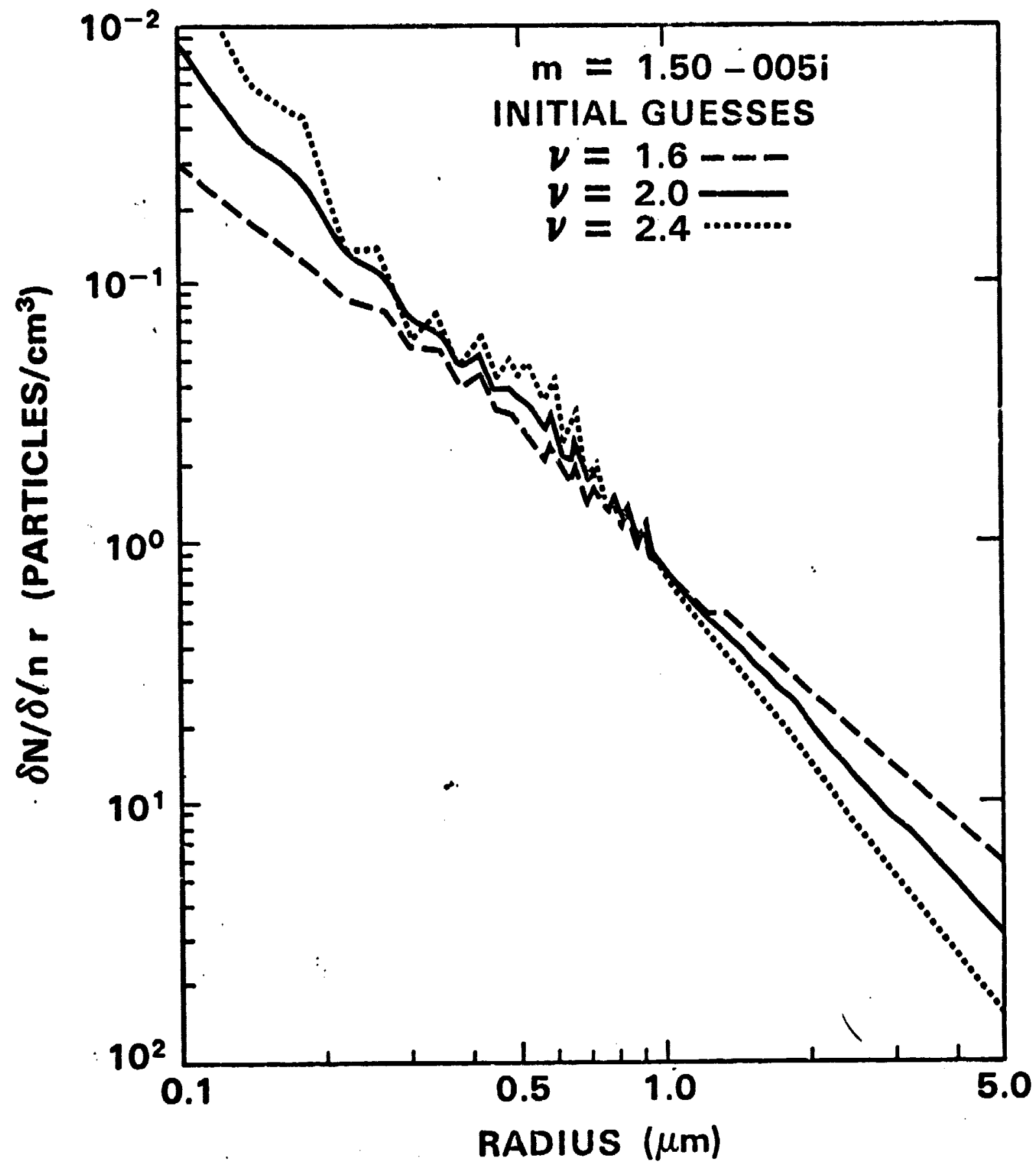

Fig.18. Size distribution inversions for March 9 experimental data. 


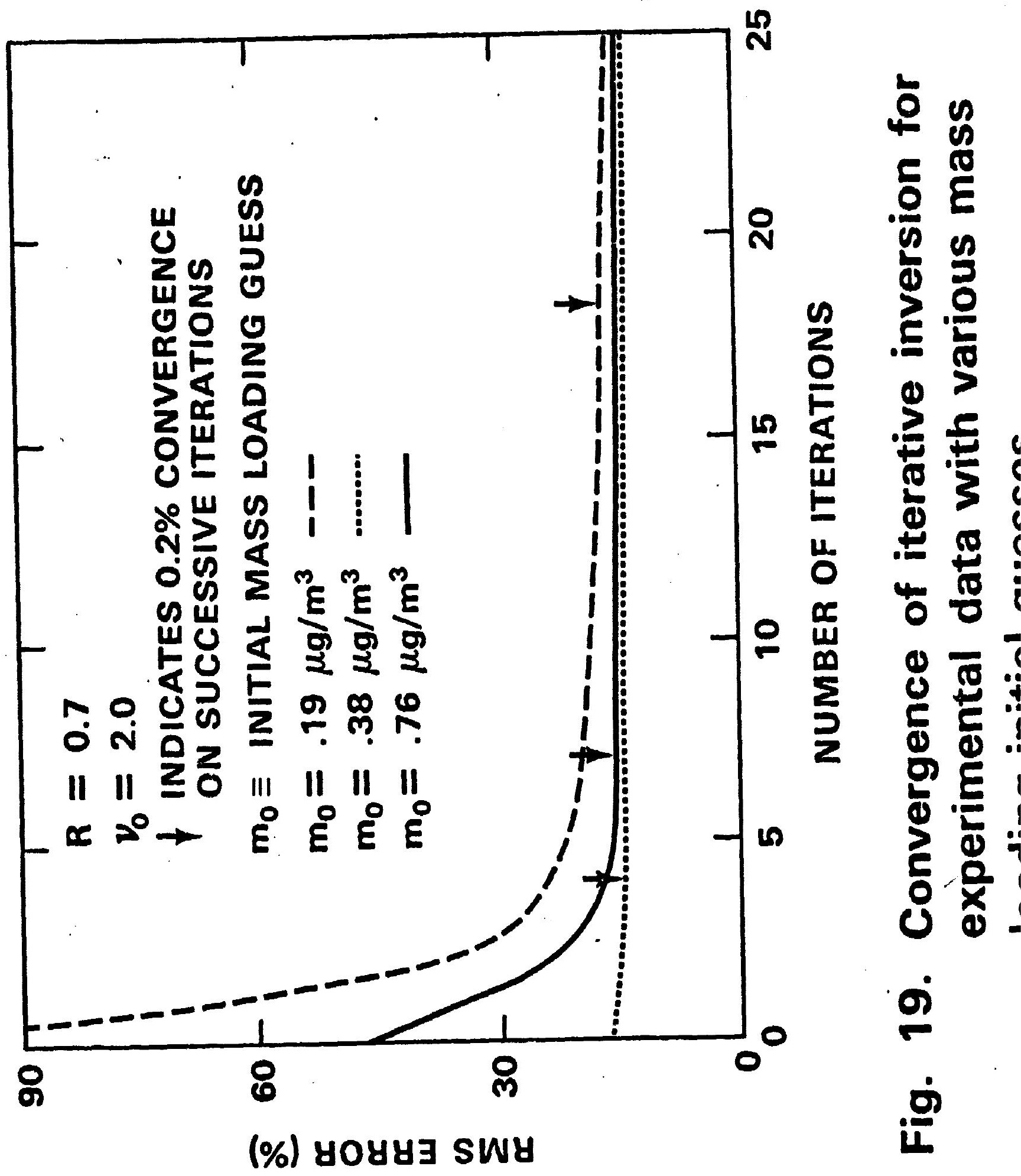




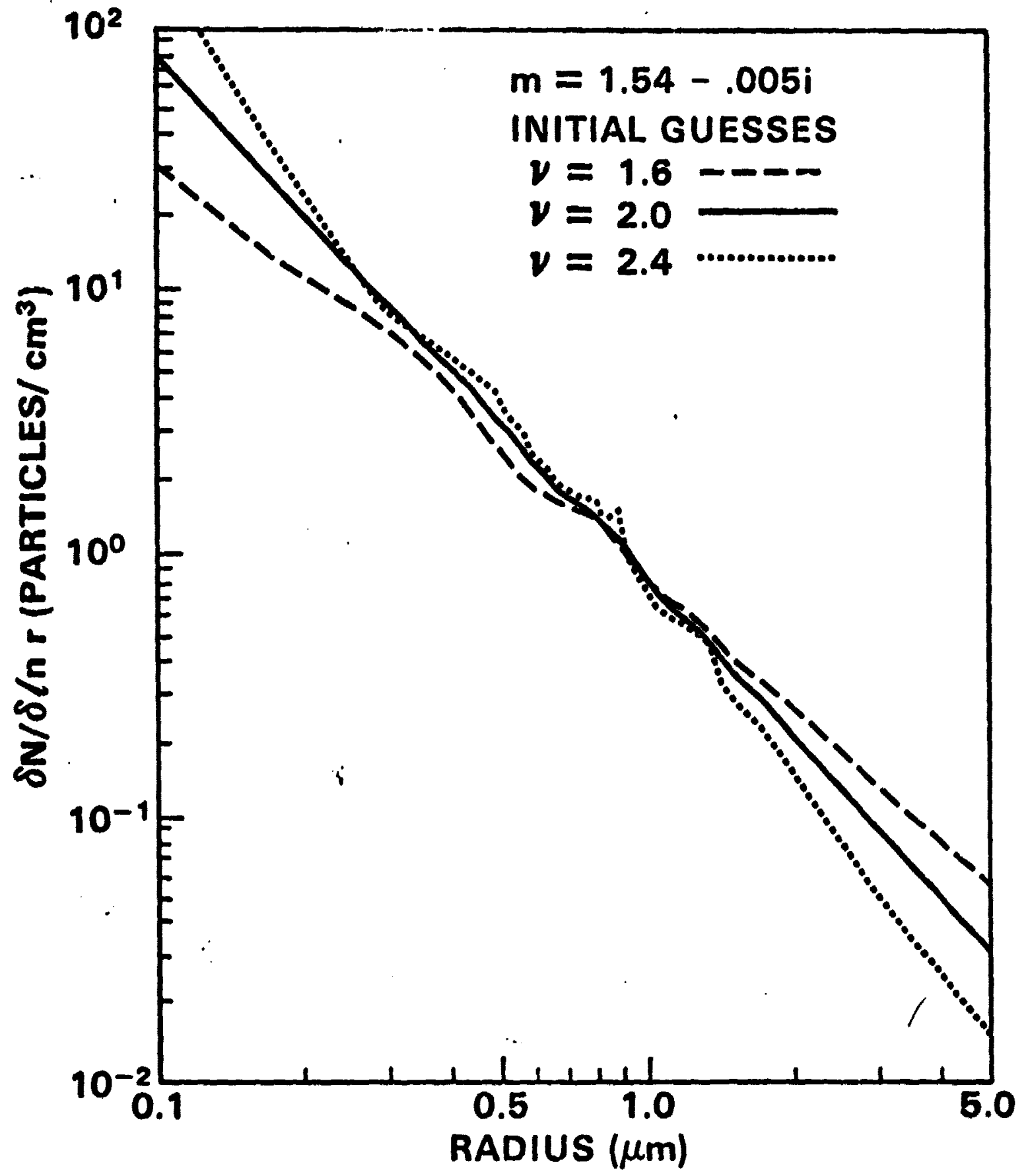

Fig. 20. Size distribution inversions for March 4t experimental data. 


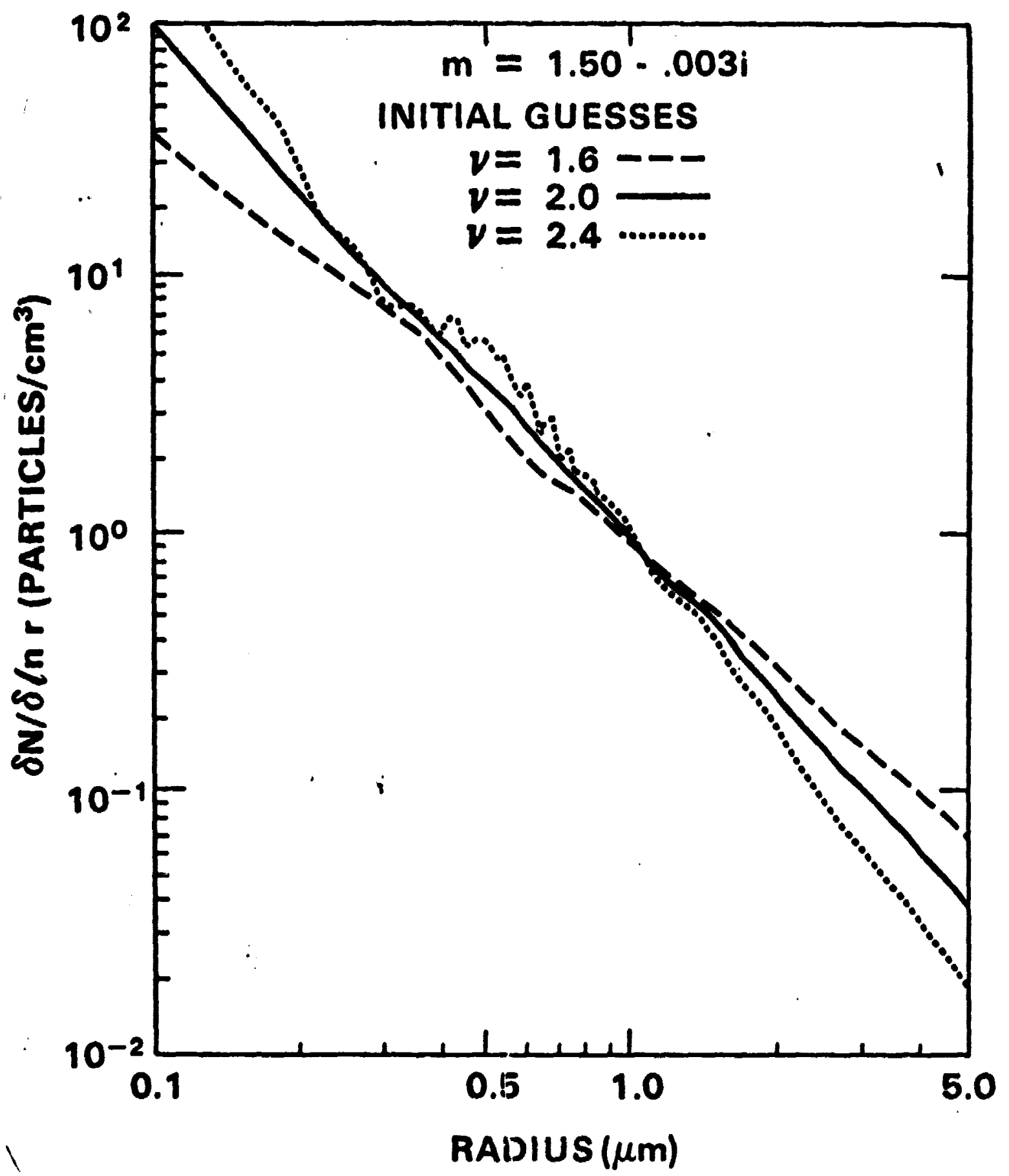

Fig. 21. Size distribution inversions for March 10 experimental data. 


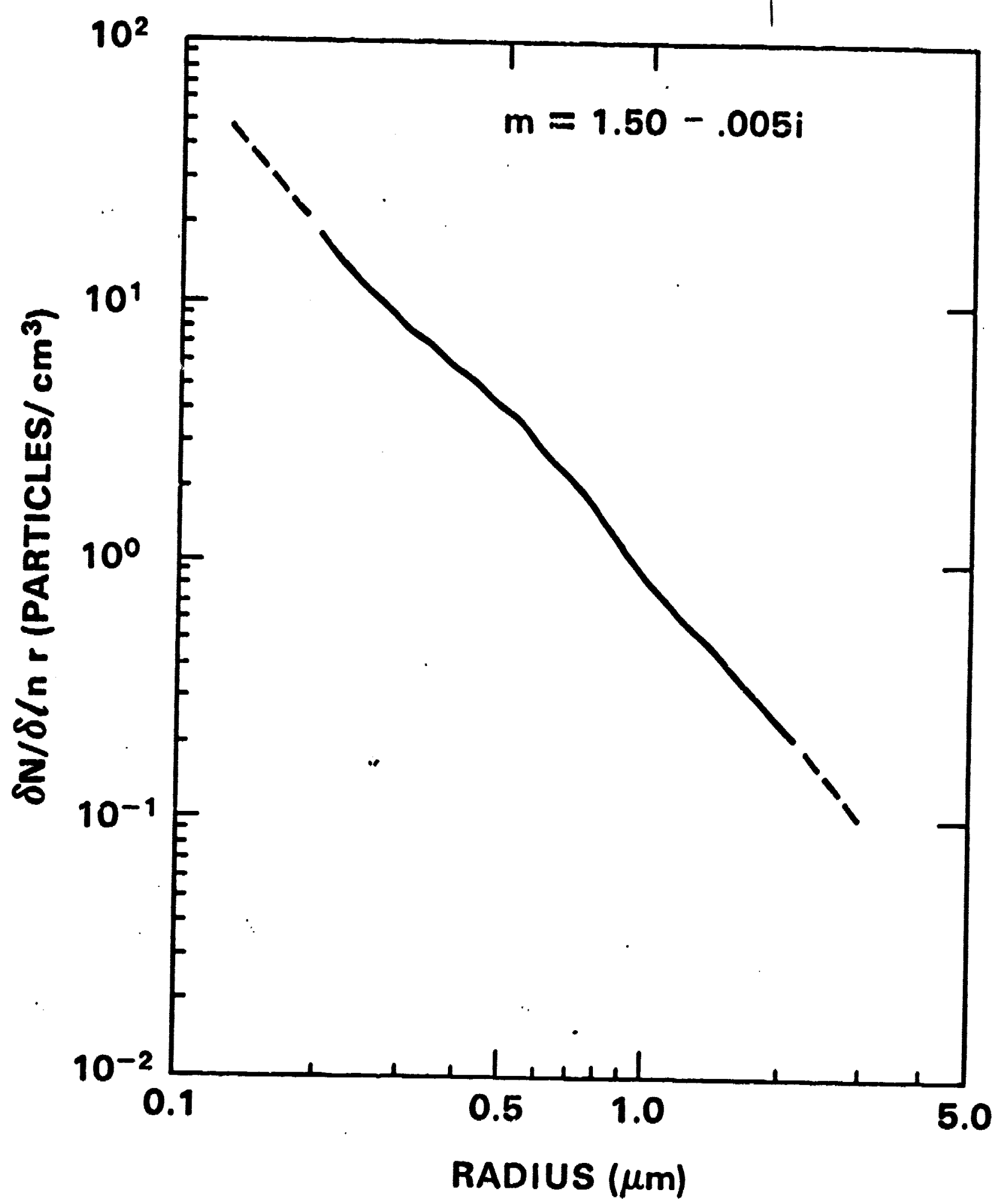

Fig. 22. Average of inverted size distributions 